\title{
ANALISIS TINGKAT EFEKTIVITAS PENERIMAAN PAJAK BUMI DAN BANGUNAN PERDESAAN DAN PERKOTAAN (PBB-P2) SEBELUM DAN SESUDAH DIALIHKAN MENJADI PAJAK DAERAH (Studi Kasus di Desa Watutumou, Kecamatan Kalawat, Kabupaten Minahasa Utara)
}

\author{
Kodoati N. Christi ${ }^{1}$, Treesje Runtu ${ }^{2}$, Stanley Kho Walandouw ${ }^{3}$ \\ ${ }^{1,2,3}$ Fakultas Ekonomi dan Bisnis. Jurusan Akuntansi. Universitas Sam Ratulangi, Jl. Kampus Bahu, Manado, \\ 95115, Indonesia. \\ E-mail : nckodoati@yahoo.com
}

\begin{abstract}
Through the implementation of law No.28 of 2009 on local taxes and lavies, the tax collection authority of the land tax and rural and urban buildings (PBB-P2) is transferred to the local government. North Minahasa district government in this case Watutumou Village is one of the villages that have potentials in the local tax sector can maximize this policy as an effort to increase acceptance in realizing development in the region. This study aims to determine the level of effectiveness of Land and Building Tax revenues before and after diverted into local taxes in Watutumou Village, the effort made by the village government to overcome the obstacles that arise in the process of acceptance of PBB-P2 and how the role of village government in optimizing the acceptance of PBB-P2. This study used descriptive quantitative method. The collection of data in this case is interview and documentation. The result of the research note that the effectiveness of $P B B-P 2$ before and after deverted into the criteria effective. But in the year before and after diverted, the realization of PBB-P2 didn't reach the target specified due to certain obstacles, so it requires the effort and role of government in increasing the acceptance of PBB-P2. For the village government can further improve the acceptance of $P B B-P 2$ with attention to human resource training, socialization and up to date data available in the village.
\end{abstract}

Keywords : PBB-P2, effectiveness, village government

\section{PENDAHULUAN}

Pembangunan nasional di Indonesia dalam segala sektor semakin hari semakin menunjukkan peningkatan dalam pertumbuhan yang ada, sehingga di lain pihak banyak dana yang diperlukan untuk membiayainya. Adapun sumber pendanaan negara yang dapat diandalkan saat ini adalah seperti pajak, migas (minyak bumi, gas alam dan batu bara), bagian laba BUMN, pendapatan BLU (Badan Layanan Umum), dan adanya bantuan luar negeri. Akan tetapi saat ini minyak dan gas yang dulunya menjadi keunggulan negara semakin menipis keberadaannya, sehingga mengharuskan pemerintah untuk lebih aktif dalam meningkatkan sumber pendanaan yang lain salah satunya dari sektor pajak. Hal ini terbukti dimana pajak saat ini merupakan penerimaan yang sangat potensial bagi negara, hal ini tertuang dalam Anggaran Penerimaan dan Belanja Negara (APBN) dimana pajak tidak hanya merupakan sumber pendapatan negara, tetapi juga merupakan salah satu penerimaan pendapatan yang digunakan dalam mengatur perekonomian negara.

Otonomi daerah yang dilakkan secara bertahap, pemerintah pusat telah mengalihkan berbagai kewenangan sebagai upaya agar pemerintah dapat mengelola daerah agar lebih berkembang. Pelaksanaan otonomi daerah dan desentralisasi fiskal selama lebih dari sepuluh tahun terakhir masih perlu secara terus menerus dilakukan penyempurnaan. Salah satu upaya tersebut adalah dengan desentralisasi fiskal dengan pengelolaan dan penerimaan, dalam hal ini pajak dan retribusi. Penerimaan dari pajak merupakan salah satu aspek penting dalam rangka meningkatkan Pendapatan Asli Daerah (PAD). 
Menurut Undang-Undang No. 28 Tahun 2009 tentang Pajak Daerah dan Retribusi Daerah menunjukkan apabila pelimpahan kewenangan pengelolaan PBB-P2 kepada pemerintah daerah dilaksanakan selambat-lambatnya oleh pemerintah kabupaten dan kota pada 1 Januari 2014. Berlakunya Undang-Undang tersebut menjadikan Pajak Bumi dan Bangunan Perdesaan dan Perkotaan yang selanjutnya disebut PBB-P2 dari Pajak Pusat menjadi Pajak Daerah diharapkan mampu menjadi salah satu sumber penerimaan PAD yang penting bagi setiap daerah.

Pertumbuhan dan perekonomian di Kabupaten Minahasa Utara seiring berjalannya waktu mengalami peningkatan dari tahun ke tahun. Desa Watutumou merupakan salah satu desa yang memiliki potensi dalam sektor pajak, khususnya Pajak Bumi dan Bangunan Perdesaan dan Perkotaan (PBB-P2). Di mana desa ini memiliki pembangunan infrastruktur yang semakin meingkat, terdapat pabrik yakni pabrik Big Land, serta beberapa gudang antara lain : Trakindo, Honda (PT. Daya Adicipta Wisesa), Multi Mart, juga beberapa ruko yang termasuk didalamnya minimarket Alfamart dan Indomaret yang berada tepat di Jl. Raya Manado-Bitung dan masih masuk dalam wilayah Desa Watutumou, serta peningkatan jumlah penduduk yang signifikan karena adanya pembangunan perumahan, salah satunya Perumahan Viola. Pemerintah Desa Watutumou sendiri telah melaksanakan pengalihan pajak daerah terhitung mulai 1 Januari 2014. Adapun tujuan yang ingin dicapai dalam penelitian ini untuk mengetahui tingkat efektivitas penerimaan pajak bumi dan bangunan perdesaan dan perkotaan (pbb-p2) sebelum dialihkan dan sesudah dialihkan menjadi pajak daerah.

\section{TINJAUAN PUSTAKA}

\subsection{Konsep Akuntansi Pajak}

Menurut Djoko Muljono (2014 : 3), menyatakan bahwa Akuntansi Pajak adalah bidang akuntansi yang berkaitan dengan perhitungan perpajakan, yang mengacu pada peraturan, undang-undang, dan aturan pelaksanaan perpajakan.

\subsection{Konsep Perpajakan \\ Definisi Pajak}

Definisi pajak menurut Undang-Undang (UU) Pajak Nomor 28 tahun 2007 menyatakan pajak adalah kontribusi wajib kepada negara yang bersifat memaksa berdasarkan UU dengan tidak mendapatkan imbalan secara langsung dan digunakan untuk keperluan negara demi kemakmuran dan kesejahteraan rakyat.

\section{Fungsi Pajak}

Menurut Mardiasmo (2016:1) pajak mempunyai beberapa fungsi, yaitu:

1. Fungsi Anggaran (Budgeter)

2. Fungsi Mengatur (Regulerend)

\subsection{Pengalihan PBB-P2 Sebagai Pajak Daerah}

Pengalihan pengelolaan Pajak Bumi dan Bangunan Perdesaan dan Perkotaan (PBB-

P2) dari Pemerintah Pusat kepada Pemerintah Daerah merupakan suatu bentuk tindak lanjut kebijakan otonomi daerah dan desentralisasi fiskal (Bussines News, 2014). Bentuk kebijakan tersebut dituangkan ke dalam Undang-undang Nomor 28 Tahun 2009 tentang Pajak Daerah dan Retribusi Daerah. Hal ini adalah titik balik dalam pengelolaan PBB-P2. Dengan pengalihan ini maka kegiatan proses pendataan, penilaian, penetapan, pengadministrasian, pemungutan/penagihan dan pelayanan PBB-P2 akan diselenggarakan oleh Pemerintah Daerah (Dirjen Pajak, 2013).

Tujuan pengalihan pengelolaan PBB-P2 menjadi pajak daerah sesuai dengan Undang-undang No. 28 Tahun 2009 tentang Pajak Daerah dan Retribusi Daerah adalah :

1. Meningkatkan akuntabilitas penyelengaraan otonomi darerah 
2. Memberikan peluang baru kepada daerah untuk mengenakan pungutan baru (menambah jenis pajak daerah dan retribusi daerah

3. Memberikan kewenangan yang lebih besar dalam perpajakan dan retribusi dengan memperluas basis pajak daerah

4. Memberikan kewenangan kepada daerah dalam penetapan tariff pajak daerah

5. Menyerahkan fungsi paak sebagai instrument penganggaran dan pengaturan pada daerah.

Dengan terbitnya Undang-undang Nomor 28 Tahun 2009 tentang Pajak Daerah dan Ratribusi Daerah, Pemerintah Daerah kini mempunyai tambahan sumber pendapatan asli daerah (PAD) yang berasal dari Pajak Daerah, sehingga saat ini jenis pajak Kabupaten/Kota terdiri dari sebelas jenis pajak, yaitu Pajak Hotel, Pajak Restoran, Pajak Hiburan, Pajak Reklame, Pajak Penerangan Jalan, Pajak Mineral Bukan Logam dan Batuan, Pajak Parkir, Pajak Air Tanah, dan Pajak Sarang Burung Walet, Pajak Bumi dan Bangunan Perdesaan dan Perkotaan, dan Bae Perolehan Hak atas Tanah dan Bangunan.

Dengan pengalihan ini, penerimaan PBB-P2 akan sepenuhnya masuk ke pemerintah kabupaten/kota sehingga diharapkan mampu meningkatkan jumlah pendapatan asli daerah. Pada saat PBB-P2 dikelola pemerintah pusat, pemerintah kabupaten/kota hanya mendapatkan 64,8 \%. Setelah pengalihan ini, semua pendapatan dari sektor PBB-P2 akan masuk kedalam kas pemerintah daerah (Dirjen Pajak, 2012).

\subsection{Efektivitas} berikut :

Terdapat beberapa pengertian efektivitas (dalam Musa Abdul Jabbar, 2012) sebagai

1) Menurut Kartikahadi

"Efektivitas adalah produk akahir kegiatan operasi telah mencapai tujuannya baik ditinjau dari segi kualitas hasil, kualitas kerja, maupun batas waktu yang ditargetkan".

2) Menurut Syahrul dan Afdinizar

"Efektivitas adalah tingkat dimana kinerja sesungguhnya (actual) sebanding dengan kinerja yang ditargetkan". berikut :

Adapun rumus perhitungan efektivitas menurut Halim (2001:164) adalah sebagai

$$
\text { Efektivitas PBB }=\frac{\text { Realisasi PBB }}{\text { Target PBB }} \times 100 \%
$$

Untuk mengatur nilai efektivitas secara lebih rinci digunakan kriteria berdasarka Kepmendagri No. 690.900.327 Tahun 1996 tentang pedoman kriteria efektivitas yang disusun dalam tabel berikut ini :

Tabel 2.5 Kriteria Penilaian Efektivitas

\begin{tabular}{|l|l|}
\hline Persentase (\%) & Kriteria \\
\hline$>100$ & Sangat Efektif \\
\hline $90-100$ & Efektif \\
\hline $80-90$ & Cukup Efektif \\
\hline $60-80$ & Kurang Efektif \\
\hline$<60$ & Tidak Efektif \\
\hline
\end{tabular}

Sumber : Depdagri, Kepmendagri No. 690.900.327 (Rima Adelina, 2012) 


\subsection{Penelitian Terdahulu}

1. Rudi Saputro/2014, "Efektivitas Penerimaan Pajak Bumi dan Bangunan Perdesaan dan Perkotaan (PBB-P2) terhadap Peningkatan Penerimaan Pendapatan Asli Daerah". (Studi Kasus pada Dinas Pendapatan Pengelolaan Keuangan Kota Surabaya). Tujuan dari penelitian ini adalah untuk mengetahui tingkat efektivitas Pajak Bumi dan Bangunan Perdesaan dan Perkotaan (PBB-P2) Kota Surabaya dan tingkat efektivitas penerimaan PBB-P2 terhadap peningkatan penerimaan PAD Kota Surabaya. Metode Penelitian Deskriptif Kualitatif. Hasil Penelitian Rata-rata tingkat efektivitas penerimaan PBB Perkotaan Surabaya pada saat dikelola oleh DJP (2010-2010) menunjukkan hasil yang lebih baik dibandingkan pada saat PBB tersebut dikelola oleh DPPK Kota Surabaya. .(2011-2013) yaitu 86,45\% dengan kriteria nilai interpretasi cukup efektif dan $76,38 \%$ oleh DPPK Kota Surabaya dengan nilai interpretasi kurang efektif. Kontibusi PBB Perkotaan Surabaya terhadap PAD Kota Surabaya dalam tiga tahun periode 2011-2013 mengalami penurunan.

2. Shavira Maulyda/2016, "Analisis Perbandingan Pajak Bumi dan Bangunan Sebelum dan Setelah Pengalihan Menjadi Pajak Daerah di Kelurahan yang ada di Kota Pekanbaru". Tujuan Penelitian untuk mendapatkan bukti empiris dan menganalisa perbedaan kemudahan membayar PBB sebelum peralihan menjadi Pajak Daerah, mendapatkan bukti empiris dan menganalisa perbedaan target PBB. Matode Penelitian Kuantitatif. Hasil Penelitian tidak terdapat perbedaan antara target PBB sebelum dan setelah pengalihan PBB menjadi pajak daerah. Hal ini mungkin terjadi karena target mengalami fluktuasi atau ketidakstabilan setiap tahunnya. Terdapat perbedaan yang signifikan dalam membayar PBB sebelum dan setelah pengalihan menjadi pajak daerah, apabila ada WP yang tidak mengerti bagaimana cara membayar PBB maka mereka bisa langsung bertanya langsung kepada petugas PBB di Dinas Pendapatan Daerah Kota Pekanbaru.

\section{PENELITIAN}

\subsection{Jenis Penelitian}

Jenis Penelitian yang digunakan oleh penulis adalah deskriptif. Menurut Sugiyono (2015:147) menyatakan bahwa: "Metode deskriptif adalah metode yang digunakan untuk mendeskripsikan atau menggambarkan data yang telah terkumpul sebagaimana adanya tanpa bermaksud membuat kesimpulan yang berlaku untuk umum atau generalisasi".

\subsection{Tempat dan Waktu Penelitian}

Tempat yang dipilih untuk melakukan penelitian adalah Kantor Desa Watutumou Kecamatan Kalawat, Kabupaten Minahasa Utara, waktu penelitian dilaksanakan pada bulan Juli-Agustus 2017.

\subsection{Metode Pengumpulan Data \\ Jenis Data}

Data adalah sekumpulan informasi yang diperlukan untuk pengambilan keputusan (Kuncoro, 2011). Peneliti menggunakan data kuantitatif berupa daftar Laporan Target dan Realisasi PBB-P2 di DesaWatutumou tahun sebelum dan sesudah dialihkan menjadi Pajak Daerah.

\section{Sumber Data}

Indrianto dan Supomo (2014) menyatakan sumber data penelitian terdiri atas :

1. Data Primer adalah sumber data penelitian yang diperoleh langsung dari sumber asli (tidak melalui perantara). Pada penelitian ini data-data yang termasuk dalam data primer diantaranya berupa hasil wawancara dengan pihak Pemerintah Desa.

2. Data sekunder adalah sumber data penelitian yang diperoleh peneliti secara tidak langsung melalui perantara (diperoleh dan dicatat oleh pihak lain), yang termasuk data 
sekunder dari penelitian ini diantaranya berupa tabel Laporan Target dan Realisasi PBB-P2 Desa Watutumou, beserta lampirannya.

\section{Teknik Pengumpulan Data}

1. Observasi dan Wawancara

2. Dokumentasi

\subsection{Metode Analisis}

Metode analisis yang digunakan dalam penelitian ini adalah metode penelitian deskriptif dengan pendekatan secara kuantitatif. Yaitu metode deskriptif untuk mendapatkan gambaran lebih jelas dan secara terperinci mengenai suatu keadaan berdasarkan data ata informasi yang telah didapatkan. Data yang dimaksudkan adalah data Laporan Target dan Realisasi Penerimaan PBB-P2 di Desa Watutumou. Kemudian data atau informasi tersebut dikumpulkan sehingga didapatkan informasi yang diprlukan untuk menganalisis masalah yang ada. Menggunakan pendekatan kuantitatif karena penelitian yang dilakukan adalah penelitian yang menekankan analisisnya pada data-data numeric (angka) dan menggunakan rumus dalam penelitian ini menggunakan rumus efektivitas.

\section{HASIL ANALISIS DAN PEMBAHASAN}

\subsection{Gambaran Umum}

Desa Watutumou adalah salah satu desa dari wilayah Kecamatan Kalawat Kabupaten Minahasa Utara yang terletak $4 \mathrm{~km}$ dari Kota Manado. Desa Watutumou mampunyai luas wilayah sekitar 717,5 hektar. Batas administrative Desa Watutumou adalah sebagai berikut : batas wilayah utara : Desa Paniki Atas dan Desa Matungkas, batas wilayah selatan : Desa Kuwil dan Desa Sawangan, batas wilayah timur : Desa Kolongan, Desa Kolongan Tetempangan, Desa Watutumou II, Desa Watutumou III dan Desa Kawangkoan Baru, batas wilayah barat : Desa Maumbi. Memiliki iklim tropis yang mempunyai pengaruh langsung terhadap pola tanam yang ada di Desa Watutumou Kecamatan Kalawat.

Pada tahun 2003, terjadi pemekaran wilayah kabupaten/kecamatan, menjadi Kbupaten Minahasa Utara dengan wilayah kecamatan yaitu Kecamatan Kalawat. Dan pada tahun yang sama ditetapkan yaitu : Kepala Desa manjadi Hukum Tua, wilayah Dusun menjadi Jaga dan dipakai sampai saat ini. Dan pada tahun 2004 terjadi pemekaran Desa Watutumou menjadi 3, yaitu : Desa Watutumou ( Desa Watutumou I ), Desa Watutumou II, Desa Watutumou III. Pada tahun 2012 Desa Watutumou memiliki wilayah pemerintahan 14 jaga.

Desa Watutumou mempunyai penduduk 3346 jiwa tahun 2016 yang tersebar dalam 14 wilayah jaga. Secara rinci jumlah penduduk dapat dilihat pada table sebagai berikut : 


\section{Tabel 4.1}

Jaga, Jumlah Jiwa dan Jumlah KK di Desa Watutumou

\begin{tabular}{|c|c|c|c|c|}
\hline \multirow{2}{*}{ Jaga } & \multicolumn{3}{|c|}{ Jumlah Jiwa } & Jumlah \\
\cline { 2 - 4 } & L & P & Total & KK \\
\hline I & 97 & 87 & 184 & 60 \\
\hline II & 96 & 94 & 190 & 63 \\
\hline II & 112 & 141 & 253 & 69 \\
\hline IV & 105 & 117 & 222 & 66 \\
\hline V & 150 & 159 & 309 & 92 \\
\hline VI & 96 & 100 & 196 & 58 \\
\hline VII & 118 & 128 & 246 & 72 \\
\hline VIII & 129 & 125 & 254 & 70 \\
\hline IX & 133 & 119 & 252 & 62 \\
\hline X & 163 & 146 & 309 & 86 \\
\hline XI & 282 & 276 & 558 & 138 \\
\hline XII & 75 & 81 & 156 & 59 \\
\hline XIII & 21 & 25 & 46 & 13 \\
\hline XIV & 88 & 83 & 171 & 51 \\
\hline Jumlah & 1665 & 1681 & 3346 & 959 \\
\hline data dar & Desa Watutumounn \\
\hline
\end{tabular}

Sumber : data dari Desa Watutumou

Demikian halnya dengan pemerintah Desa Watutumou harus memiliki visi dan misi yang ditetapkan oleh pemerintah Desa Watutumou yaitu sebagai berikut :

1) Visi

"Meningkatkan Kualitas Sumber Daya Manusia dan Menggali Sumber Daya Alam Menuju Masyarakat yang Maju, Aman dan Religius"

2) Misi

a. Meningkatkan sarana dan prasarana gedung kantor desa.

b. Membangun desa untuk kesejahteraan rakyat.

c. Meningkatkan keamanan dan ketertiban masyarakat.

d. Melestarikan dan memmanfaatkan sumber daya alam serta kebersihan lingkungan hidup.

e. Meningkatkan pemanfaatan lahan pertanian, peternakan, dan perikanan.

f. Meningkatkan kualitas pendidikan dan kesehatan.

g. Meningkatkan pendapatan usaha kecil masyarakat ( home industry ).

h. Menigkatkan sarana dan prasarana jalan desa/lorong/jalan setapak termasuk jalan ke pekuburan.

i. Meningkatkan sarana dan prasarana olahraga.

j. Memanfaatkan alokasi dan desa sesuai dengan sarana peruntukannya.

k. Melaksanakan pengelolaan keuangan desa yang transparan dan akuntabel.

1. Meningkatkan hubungan kerjasama yang harmonis dengan BPD serta mitra pemerintah desa.

m. Membangun kerjasama dengan pihak swasta dan stakeholder dalam mengembangkan potensi desa/pendapatan asli desa.

n. Melestarikan dan menjadikan "Batu Bertumbuh" (WATUTUMOU) sebagai objek wisata.

\subsection{Hasil Penelitian}

\subsubsection{Laporan Target dan Realisasi PBB-P2 Desa Watutumou Sebelum dialihkan menjadi Pajak Daerah}

Laporan target dan realisasi di Desa Watutumou, tahun sebelum dialihkan menjadi pajak daerah, dapat dilihat pada tabel dibawah ini : 


\section{Tabel 4.2}

Laporan Target dan Realisasi PBB-P2 Tahun 2011-2013

\begin{tabular}{|c|r|r|}
\hline Tahun & Target (Rp) & \multicolumn{1}{|c|}{ Realisasi (Rp) } \\
\hline 2011 & $297,822,434$ & $268,026,126$ \\
\hline 2012 & $325,466,209$ & $310,475,873$ \\
\hline 2013 & $336,428,187$ & $320,198,725$ \\
\hline
\end{tabular}

Sumber : Laporan Badan Keuangan, Kantor Gabungan Pemkab Minut

Berdasarkan tabel 4.2 dapat dilihat bagaimana laporan target dan realisasi PBB-P2 Desa Watutumou sebelum dialihkan menjadi Pajak Daerah. Kita dapat melihat bahwa pada tahun 2011-2013 yang menjadi patokan sebagai tahun sebelum PBB-P2 dialihkan menjadi pajak daerah, target yang ditetapkan masih rendah yakni berkisaran 200-300 juta setiap tahunnya, serta realisasinya belum juga mencapai target yang telah ditetapkan. Target yang sudah ditetapkan dan realisasi yang sudah dicapai di Desa Watutumou menjadi dasar perhitungan tingkat efektivitas penerimaan PBB-P2. Perhitungan tingkat efektivitas Penerimaan Pajak Bumi dan Bangunan tahun 2011-2013 dapat menggunakan rumus berikut :

$$
\text { Efektivitas }=\frac{\text { Realisasi PBB }-\mathrm{P} 2}{\text { Target Penerimaan PBB }-\mathrm{P} 2} \times 100 \%
$$

Sumber : Depdagri,Kepmendagri No.690.900.327 (Rima Adelina,2012)

Berdasarkan rumus diatas, maka tingkat efektivitas Pajak Bumi dan Bangunan Perdesaan dan Perkotaan Desa Watutumou tahun 2011-2013 dapat dihitung sebagai berikut :

a. Tingkat Efektivitas PBB-P2 Tahun 2011

$$
\begin{aligned}
& =\frac{\text { Rp. } 268.026 .126}{\text { Rp. } 297.822 .434} \times 100 \% \\
& =90 \%
\end{aligned}
$$

b. Tingkat Efektivitas PBB-P2 Tahun 2012

$$
\begin{aligned}
& =\frac{\text { Rp. } 310 \cdot 475 \cdot 873}{\text { Rp. } 325 \cdot 466 \cdot 209} \times 100 \% \\
& =95,39 \%
\end{aligned}
$$

c. Tingkat Efektivitas PBB-P2 Tahun 2012

$$
\begin{aligned}
& =\frac{\text { Rp. } 320 \cdot 198.725}{\text { Rp. } 336.428 .187} \times 100 \% \\
& =95,18 \%
\end{aligned}
$$

\subsubsection{Laporan Target dan Realisasi PBB-P2 Desa Watutumou Sesudah dialihkan menjadi Pajak Derah}

Laporan target dan realisasi di Desa Watutumou tahun sesudah dialihkan menjadi pajak daerah, dapat dilihat pada tabel berikut ini : 


\section{Tabel 4.3}

Laporan Target dan Realisasi PBB-P2 Tahun 2014-2016

\begin{tabular}{|c|c|r|}
\hline Tahun & Target (Rp) & Realisasi (Rp) \\
\hline 2014 & $358,622,049$ & $316,412,892$ \\
\hline 2015 & $432,824,875$ & $410,653,317$ \\
\hline 2016 & $394,611,131$ & $358,016,915$ \\
\hline
\end{tabular}

Sumber : Laporan Badan Keuangan, Kantor Gabungan Pemkab Minut

Berdasarkan tabel 4.3 dapat dilihat bagaimana laporan target dan realisasi PBB-P2 Desa Watutumou sesduah dialihkan menjadi pajak daerah. Pada tahun 2014-2016 dimana PBB-P2 telah dialihkan menjadi pajak daerah terjadi peningkatan target PBB-P2 yang harus dicapai, sama seperti tahun sebelum dialihkan realisasinya pun belum mencapai target yang ditentukan, namun dilihat pada tahun 2015 terjadi kenaikan target serta realisasi yang cukup besar yakni target sebesar Rp. 432,824,874 dan realisasi sebesar Rp. 410,653,317. Kemudian kembali mengalami penurunan ditahun berikutnya yaitu tahun 2016, dengan target sebesar Rp. 394,611,131 danrealisasi sebesar Rp. 358,016,915. Target yang sudah ditetapkan dan realisasi yang sudah dicapai di Desa Watutumou menjadi dasar perhitungan tingkat efektivitas penerimaan PBB-P2. Perhitungan tingkat efektivitas Penerimaan Pajak Bumi dan Bangunan tahun 2014-2016 dapat menggunakan rumus sebagai berikut :

$$
\text { Efektivitas }=\frac{\text { Realisasi PBB }-\mathrm{P} 2}{\text { Target Penerimaan PBB }-\mathrm{P} 2} \times 100 \%
$$

Sumber : Depdagri,Kepmendagri No.690.900.327 (Rima Adelina,2012)

Berdasarkan rumus diatas, maka tingkat efektivitas Pajak Bumi dan Bangunan Perdesaan dan Perkotaan Desa Watutumou tahun 2014-2016 dapat dihitung sebagai berikut:

a. Tingkat Efektivitas PBB-P2 Tahun 2014

$$
\begin{aligned}
& =\frac{\text { Rp. } 316.412 .892}{\text { Rp. 358.622.049 }} \times 100 \% \\
& =88,23 \%
\end{aligned}
$$

b. Tingkat Efektivitas PBB-P2 Tahun 2015

$$
\begin{aligned}
& =\frac{\text { Rp. } 410 \cdot 653 \cdot 317}{\text { Rp. } 432 \cdot 824 \cdot 875} \times 100 \% \\
& =94,88 \%
\end{aligned}
$$

c. Tingkat Efektivitas PBB-P2 Tahun 2016

$=\frac{\text { Rp. } 358.016 .915}{\text { Rp. 394.611.131 }} \times 100 \%$

$=90,73 \%$

\subsection{Pembahasan}

\subsubsection{Tingkat Efektivitas Penerimaan PBB-P2 Sebelum Dialihkan}

Tingkat efektivitas Pajak Bumi dan Bangunan Perdesaan dan Perkotaan Desa Watutumou tahun 2011-2013 dapat dilihat pada tabel dibawah ini : 


\section{Tabel 4.4}

Efektivitas Penerimaan PBB-P2 Desa Watutumou Tahun 2011-2013

\begin{tabular}{|c|c|c|c|c|}
\hline Tahun & Target (Rp) & Realisasi (Rp) & $\begin{array}{c}\text { Persentase } \\
(\%)\end{array}$ & Kriteria \\
\hline 2011 & $297,822,434$ & $268,026,126$ & 90 & Efektif \\
\hline 2012 & $325,466,209$ & $310,475,873$ & 95.39 & Efektif \\
\hline 2013 & $336,428,187$ & $320,198,725$ & 95.18 & Efektif \\
\hline \multicolumn{3}{|c|}{ Rata-Rata } & 93.52 & Efektif \\
\hline
\end{tabular}

Sumber : Data Olahan

Tabel 4.4 menunjukkan tingkat efektivitas penerimaan PBB-P2 Desa Watutumou yang tiap tahunnya masuk pada kriteria efektif. Pencapaian penerimaan PBB-P2 masingmasing sebesar 90,00\% di tahun 2011, 95,39\% di tahun 2012 dan 95,18\% di tahun 2013. Bila melihat rata-rata persentase PBB-P2 sebelum dialihkan masuk pada kriteria efektif, yakni sebelum dialihkan rata-rata sebesar 93,52\%. Walaupun sudah masuk pada kriteria efektif, namun penerimaan PBB-P2 sebelum dialihkan belum mencapai target yang ditetapkan.

Berdasarkan observasi lapangan hal ini disebabkan oleh data yang diserahkan oleh pemerintah desa ke kabupaten tidak akurat yang pada akhirnya menimbulkan masalah yakni timbulnya ketidakadilan terhadap WP yang akan melakukan pembayaran PBB-P2 yang membuat WP terlambat bahkan tidak mau membayarkan kewajiban mereka yang pada akhirnya menjadi hambatan dalam proses penerimaan PBB-P2 di Desa Watutumou. Ini dikarenakan adanya manipulasi pajak yang dilakukan seperti menyembunyikan objek pajak, dan tidak jujur dalam melaporkan pajaknya, bahkan ini juga tidak terlepas dari penempatan personil pada bagian pengelolaan pajak di desa yang minim dan kurangnya sosialisasi serta pelatihan mengenai pengalihan pajak, khusunya PBB-P2 yang dilakukan oleh pemerintah desa setempat.

\subsubsection{Tingkat Efektivitas Penerimaan PBB-P2 Sesudah Dialihkan}

Tingkat efektivitas Pajak Bumi dan Bangunan Perdesaan dan Perkotaan Desa Watutumou tahun 2014-2016 dapat dilihat pada tabel berikut ini :

\section{Tabel 4.5}

Efektivitas Penerimaan PBB-P2 Desa Watutumou Tahun 2014-2016

\begin{tabular}{|c|c|c|c|c|}
\hline Tahun & Target (Rp) & Realisasi (Rp) & $\begin{array}{c}\text { Persentase } \\
(\%)\end{array}$ & Kriteria \\
\hline 2014 & $358,622,049$ & $316,412,892$ & 88.23 & Cukup Efektif \\
\hline 2015 & $432,824,875$ & $410,653,317$ & 94.88 & Efektif \\
\hline 2016 & $394,611,131$ & $358,016,915$ & 90.73 & Efektif \\
\hline \multicolumn{3}{|c|}{ Rata-Rata } & 91.28 & Efektif \\
\hline
\end{tabular}

Sumber : Data Olahan

Tabel 4.5 menunjukkan tingkat efektivitas penerimaan PBB-P2 Desa Watutumou sesudah dialihkan menjadi pajak daerah. Tiap tahunnya yakini tahun 2014 sampai 2016 masuk pada kriteria efektif. Pada tahun 2014 realisasi PBB-P2 di Desa Watutumou mengalami penurunan dibandingkan tahun 2013, yakni sebesar Rp. 316.412 .892 atau sebesar $1,18 \%$ dengan pencapaian penerimaan/realisasi sebesar 88,23\%. Pada tahun 2015 realisasi PBB-P2 mengalami kenaikan yang cukup signifikan yakni sebesar Rp. 410.653.371 atau sebesar 22,94\% dengan pencapaian penerimaan/realisasi sebesar 94,88\%, di tahun berikutnya yaitu tahun 2016 realisasi PBB-P2 kembali mengalami penurunan yakni sebesar Rp. 
358.016.915 atau sebesar $12,82 \%$ dengan tingkat pencapaian penerimaan/realisasi sebesar $90,73 \%$.

Melihat tingkat efektivitas penerimaan PBB-P2 Desa Watutumou sesudah dialihkan maka dapat dikatakan tingkat efektivitas penerimaan PBB-P2 di desa ini mengalami fluktuasi atau ketidakstabilan. Berdasarkan wawancara dengan Pemerintah Desa apabila terdapat hambatan yang menyebabkan ketidakstabilan dalam penerimaan PBB-P2 maka pemerintah desa berupaya untuk meningkatkan basis data mengenai PBB-P2 sehingga lebih akurat, meningkatkan sumber daya manusia melalui pelatihan atau diklat mengenai PBB serta akan dilaksanakannya sosialisasi mengenai PBB-P2 pada seluruh Wajib Pajak, bahkan akan berperan dalam memperkat proses pemungutan melalui aparat desa setiap tahunnya untuk mengoptimalkan penerimaan PBB-P2 dari target yang telah ditetapkan.

\section{KESIMPULAN DAN SARAN}

\subsection{Kesimpulan}

Berdasarkan beberapa uraian yang telah dikemukakan, maka penulis menarik kesimpulan sebagai berikut :

1. Total rata-rata penerimaan PBB-P2 Desa Watutumou sebelum dialihkan menjadi pajak daerah masuk pada kriteria efektif karena berkisar pada 90-100\% yakni sebesar 93,52\%. Walaupun, realisasi setiap tahunnya (2011-2013) tidak mencapai target yang di tentukan.

2. Total rata-rata penerimaan PBB-P2 Desa Watutumou sesudah dialihkan menjadi pajak daerah masuk pada kriteria efektif yakni sebesar 91,28\%, dengan tingkat penerimaan paling tinggi pada tahun 2015 sebsesar Rp. 410.653.317. Walaupun, realisasi setiap tahunnya (2014-2016) juga sama dengan sebelum dialihkan yaitu belum mancapai target yang di tentukan.

\subsection{Saran}

Berdasarkan hasil analisis data dan kesimpulan tentang tingkat efektivitas penerimaan PBB-P2 di Desa Watutumou, penulis mencoba mengajukan saran yang diharapkan dapat memberi manfaat adalah sebagai berikut :

1. Perlunya dilakukan up date data yang merata di Desa Watutumou untuk meningkatkan penerimaan PBB-P2 dan potensi penerimaan PBB-P2 dapat terus ditingkatkan. Perlunya dilaksanakan pemungutan PBB-P2 dengan sistem yang baik dengan sumber daya manusia yang memadai sehingga pencapaian/realisasi PBB-P2 di Desa Watutumou dapat maksimal. Kepatuhan wajib pajak juga perlu ditingkatkan dengan berbagai pendekatan, bisa pendekatan pelayanan, penetapan sanksi dan lain sebagainya.

2. Dalam meningkatkan efektivitas penerimaan PBB-P2, ada baiknya pemerintah Desa Watutumou memperhatikan faktor-faktor kecil yang mepengaruhi pelayanan terhadap masyarakat. Seperti ketersediaan berkas dan meningkatkan kompetensi aparat desa yang melaksanakan pemungtan PBB-P2. Serta adanya transparansi dalam pemungutan sehingga adanya timbal balik antara pemerintah desa dengan wajib pajak sehingga terjalin kerjasama yang baik antara keduanya.

\section{DAFTAR PUSTAKA}

Undang-Undang Nomor 28 Tahun 2009 tentang Pajak Daerah dan Retribusi Daerah. (2009). Jakarta: Diperbanyak oleh Sekretariat Negara Republik Indonesia.

Business News. (2014). Menimbang Efektivitas Pengelolaan PBB Oleh Pemda. Jakarta.

Direktorat Jendral Pajak. (2012). Pengalihan Pajak Bumi dan Bangunan Perdesaan dan Pekotaan (PBB-P2) Sebagai Pajak Daerah. content://com.sec.android.app.scbrowser/radinglist/0301104614859.mhtml. 
Djoko Supatmoto. (2015). Analisis Efektivitas Penerimaan Pajak Bumi dan Bangunan Perdesaan dan Perkotaan terhadap Peningkatan Penerimaan Pendapatan Asli Daerah di Kabupaten Lumajang.

Mardiasmo. (2016). Perpajakan Edisi Revisi. Jakarta: Andi.

Rudi Suprapto. (2014). Efektivitas Penerimaan Pajak Bumi dan Bangunan Perdesaan dan Perkotaan (PBB-P2) terhadap Peningkatan Penerimaan Pendapatan Asli Daerah (Studi Kasus Pada Dinas Pengelolaan Keuangan Kota Surabaya).

Shavira Mauldya. (2016). Analisis Perbandingan Pajak Bumi dan Bangunan Sebelum dan Setelah Pengalihan Menjadi Pajak Daerah di Kelurahan yang ada di Pekanbaru.

Siahaan. (2013). Akuntansi Perpajakan Edisi : 3. Jakarta: Salemba Empat.

Waluyo. (2013). Perpajakan Indonesia Edisi 11 Buku 1. Jakarta: Salemba Empat.

Ni Putu Dian Damaiyanti \& I Putu Ery Setiawan. (2014). Analisis Efektivitas dan Kontribusi Penerimaan PBB Terhadap PAD Kota Denpasar Tahun 2009-2013.

Nur Riza Utiarahman. (2016). Analisis Efektivitas dan Kontribusi Penerimaan Pajak Bumi dan Bangunan Perdesaan dan Perkotaan (PBB-P2) terhadap PAD Kota Tomohon. Jurnal 16. No. 02.

Prihandono, Gigih. (2014). Dampak Pengalohan PBB P2 dan BPHTB dari Pemerintah Pusat terhadap Pendapatan Daerah (Studi Kasus di Kabupaten Tulungagung). 